\title{
Daily Variability of Radon Gas in Brazilian Tropics Near Ground Level Surface
}

\author{
Inácio Malmonge Martin, Marcelo Pego Gomes, Bogos Nubar Sismanoglu and Nicolas Cruvinel Lindo \\ Department of Physics, Technological Institute of Aeronautics, São José dos Campos 12228-900, Brazil
}

Received: November 09, 2015 / Accepted: November 13, 2015 / Published: December 10, 2015

\begin{abstract}
By monitoring the ionizing radiation from minute to minute in São José dos Campos, SP, Brazil (230 S, 450 W) using Geiger counter, during January to August 2015, it has confirmed the presence of radon gas in these measures. The observation confirms the existence of a periodicity of 24 hours through the technique (Fast Fourier Transform) applied to the data set, and this cycle can be better visible in longer dry periods. On rainy days or with heavy fog in the region, this periodicity is modified or even disappears. As Geiger do not detect alpha particles due to absorption in the walls of the sensor tube, it measured X and gamma rays coming from the radon gas progeny. Radon gas $\left({ }^{222} \mathrm{Rn}\right)$ has a half-life of 19.7 minutes to decays in ${ }^{214} \mathrm{Bi}$ emitting gamma ray energy (45\%) with $0.609 \mathrm{MeV}$ which is monitored daily by Geiger. Also ${ }^{222} \mathrm{Rn}$ decays in 26.8 minutes in ${ }^{214} \mathrm{~Pb}$ giving (37\%) with $0.35 \mathrm{MeV}$ and others with less energy. It is confirmed the good performance of a Geiger tube with LND 712 working with about 500 VDC rated voltage.
\end{abstract}

Key words: Geiger, radon gas, ionizing radiation.

\section{Introduction}

Scientific journals [1] reports that geomagnetically trapped radiation was originally monitored by Russian (Soviet) spacecraft, and shortly thereafter by American spacecraft, both of them set satellites carrying Geiger counters. James Van Allen at the University of Iowa was the first to publicize the data obtained together with an understanding of the discovery of the magnetic confinement of energetic ( $\mathrm{keV}$ and $\mathrm{MeV}$ ) electrically charged particles (then primarily electrons), although others (both in the US and in Russia) had already worked on such ideas, and soon thereafter comprehensive descriptive models began to be developed [2]. So, the importance of Geiger counters in space and in near ground level surface measurements are still the main instruments to study the integrated ionizing radiation in several regions of earth and atmosphere today. Who can furnish these radiations to earth surface and low

Corresponding author: Inácio Martin, Ph.D., main research fields: magnetic field, radiation and solar plasma. altitude atmosphere? Who can supply these radiations to earth surface and near low atmosphere? The possible sources of radiation will be:

(1) Presence of local radionuclide's from the three series of disintegration and radioactive potassium $\left({ }^{40} \mathrm{~K}\right)$;

(2) Secondary cosmic radiation;

(3) Radon gas presence in the place;

(4) Radiation produced by humans.

In accord with Thomas, about 56\% (Fig. 1) of radiation received by human throughout their life come from of the radon gas radiation [3].

This ionizing radiation has enough energy to strip electrons from the atom (about $12 \mathrm{eV}$ ). The background of this integrated ionizing radiation in a given region is the sum of the four components described above. This land-based radiation of local geology decay is caused by the three series, namely: uranium-238 $\left({ }^{238} \mathrm{U}\right)$, actinium-235 $\left({ }^{235} \mathrm{U}\right)$ and thorium-232 $\left({ }^{232} \mathrm{Th}\right)$ [4]. Each decay nuclei emit radiation type alpha, beta particles, $\mathrm{X}$ and or gamma rays photons [5]. These 


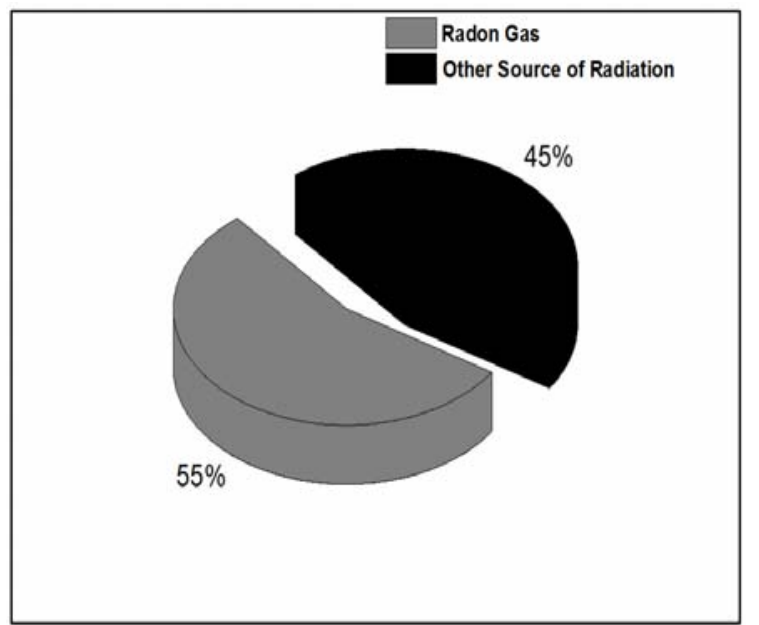

Fig. 1 Radiation received by human throughout their life.

sequences give cores radioactive isotopes natural sources belonging to each of the above radioactive series or families [6, 7].

The uranium-235 has a half-life of 713 million years while the uranium-238 has a half-life of $4.5 \times$ $10^{9}$ years. This means that there is a lower percentage of uranium-235 relative to uranium-238. Therefore, the uranium-235 is more "consumed" than the uranium-238 [8]. The other important source of ionizing radiation in the soil-air interface in the region is the presence of radon gas $\left({ }^{222} \mathrm{Rn}\right)$ who is also coming from the disintegration of uranium-238 series. Radon gas decays into ${ }^{218} \mathrm{Po}$ in alpha particles and, ${ }^{214} \mathrm{~Pb}$ and ${ }^{214} \mathrm{Bi}$ giving $\mathrm{X}$ and gamma from $0.08 \mathrm{MeV}$ to $2.20 \mathrm{MeV}$ which was measured in the air near local soil [9]. In general, radon gas is present always in the rain with winds that arrive before the cold fronts. These rains are intense and living with intense volume of radon gas.

The alpha radiation, beta, and X-gamma rays from the secondary cosmic radiation produced in the lower atmosphere are somewhat variable as a function of time. However, its intensities depend on the latitude and altitude with reference to the earth's surface [10]. The primary cosmic radiation produces true "long showers" particles of compounds and energy photons that reach the earth's surface causing ionization in the environment.
The artificial ionizing radiations are those produced by humans in medical and deontological laboratories, nuclear accelerators. However, these radiations are confined in principle, controlled in a given region. In Brazil, there is no knowledge, considering nationwide, the percentage measurement of ionizing radiation from soil, radon, cosmic and artificial. In Portugal, for example, these data are well known, that is: radon (56\%); soil (8.0\%), cosmic (8.0\%), artificial (17\%) and others (11\%) [8].

\section{Materials}

A Geiger counter is one kind of instrument very simple used for detection and monitoring during long time period of the ionizing radiation: alpha, beta particles, X-ray and low energy gamma rays. Basically, it consists in a cylinder with a pair of electrodes surrounded by special gas inside with 3 or more atmosphere of pressure, using high voltage (about 500 VDC) across them. The Fig. 2 shows the schematic view of Geiger tube and the variation on counters with applied voltage between the electrodes.

The gas used usually is helium, xenon or argon. The photon and particles enters the tube with gas and with high voltage, the ions or electrons go to produces one pulse where the count rate system is used for monitoring the present radiation. In order for the Geiger counter tube to restore itself quickly to its original state after radiation has entered, the gas added to the tube is used. For the proper use of Geiger counts, one must have the appropriate voltage between the electrodes (plateau region). Usually, the manufacture recommends the correct voltage to use for tube (V). The Ludlum 712 tube has like best work the voltage near 500 VDC (plateau region). One PC (Personal Computer) is branched to the Geiger using special associated electronics made by aware electronics, INC, USA to furnish the high voltage (DC) and provide the data acquisition each minute that can read and save in (txt) extension in the PC. 


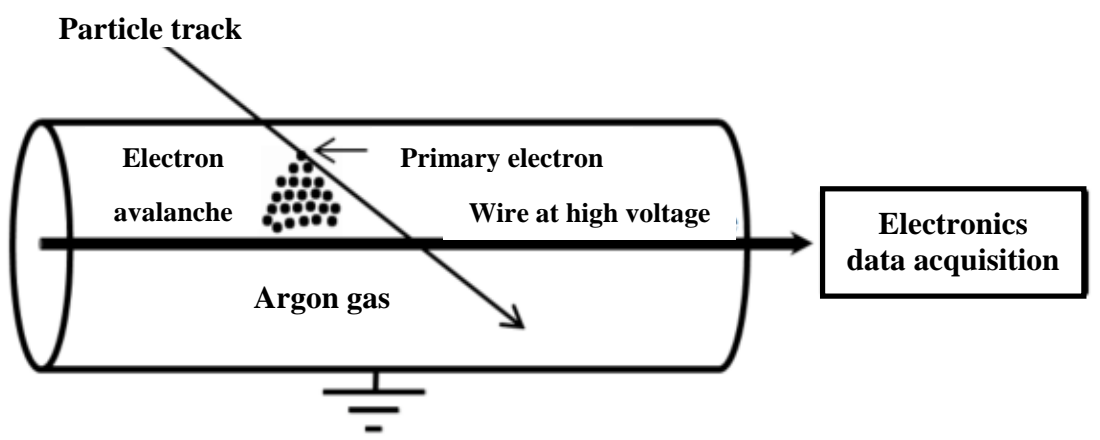

(a)

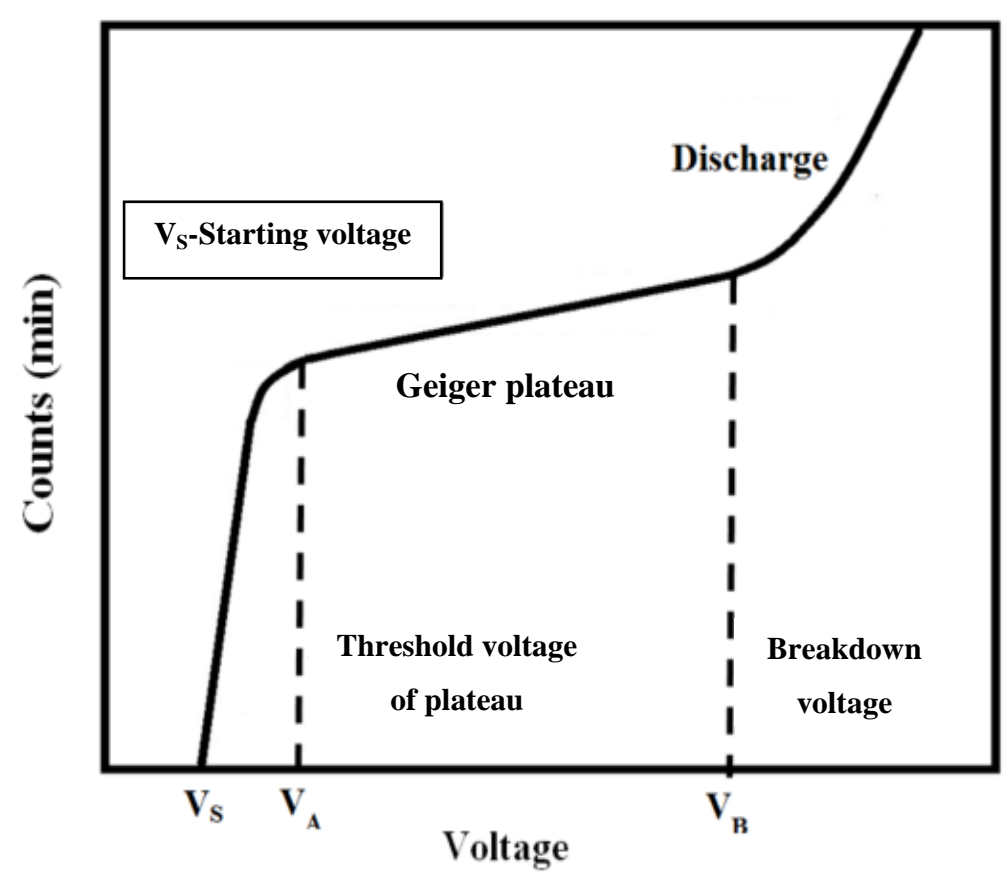

(b)

Fig. 2 (a) View of the cylinder consisting the tube with gas and electrodes with high voltage and the operating at 500VDC > VA and < VB, (b) Geiger Müller plateau region [11].

\section{A Fast Fourier Transform (FFT) computer} technique applied to the data is used to check cycles in the all data extension measured in determined time and region [12]. The Geiger was protected from direct sun and working well in $-20^{\circ} \mathrm{C}$ to $+50^{\circ} \mathrm{C}$.

\section{Experimental Results}

The measurements were performed in the period from 30/06 to 26/08 2015 with the Geiger placed in a room of Electricity and Magnetism Laboratory of the Department of Physics, ITA, in São José dos Campos,

\section{SP, Brazil (Fig. 4).}

These measures in the period from July to August 2015 (44,000 $\mathrm{min}$ to $80,000 \mathrm{~min}$ ) had few influences of intense rain (Fig. 4).

With dry periods are observed cycles of 1 day with a maximum in the vicinity of 12 hours in local time and minimum close to 24 hours same local time. This better view is clearly perceived between 44,000 minutes and 72,000 minutes as shown in Fig. 5, making a zoom part of the Fig. 3 above.

A detailed analysis of the measures shown in Figs. 


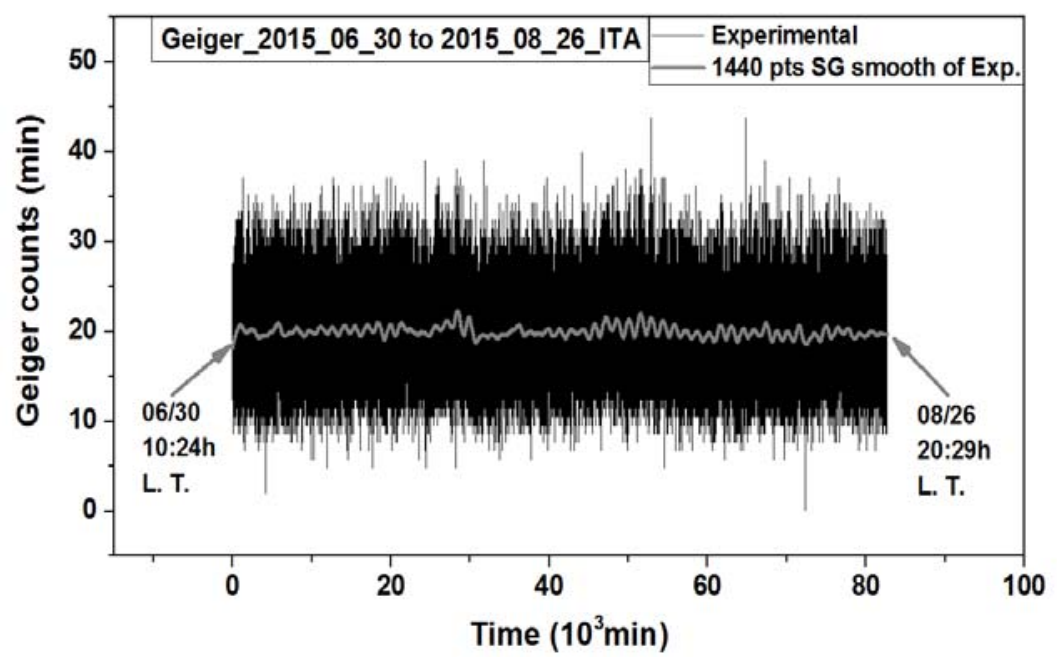

Fig. 3 Monitoring of ionizing radiation using Geiger RM-60 in a room of the department of physics of ITA in São José dos Campos in 2015.

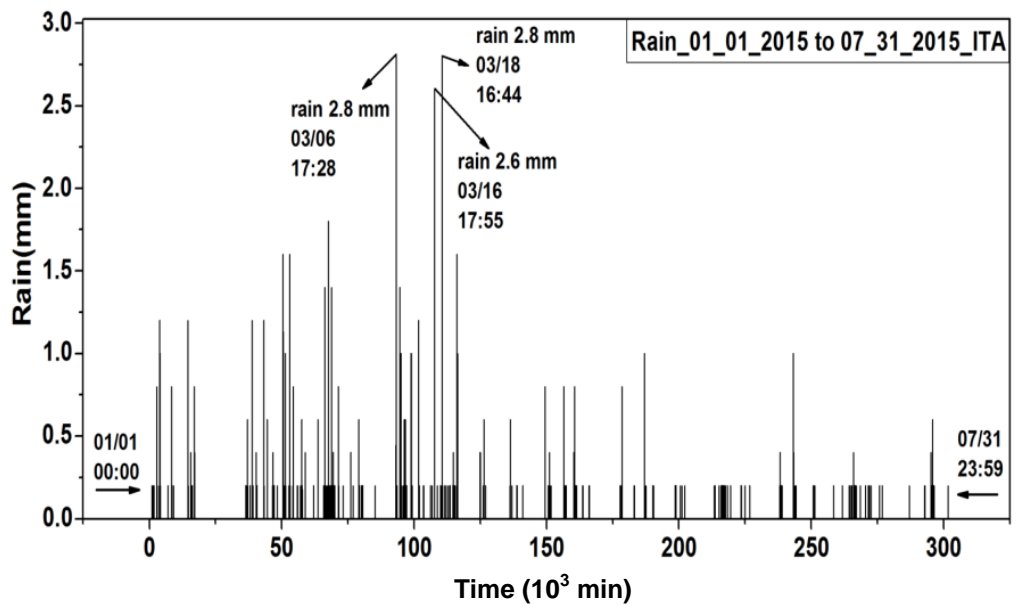

Fig. 4 Intensity of rain in (mm) with pluviometer placed in same localization of Geiger during January, 1 to July, 31 of 2015.

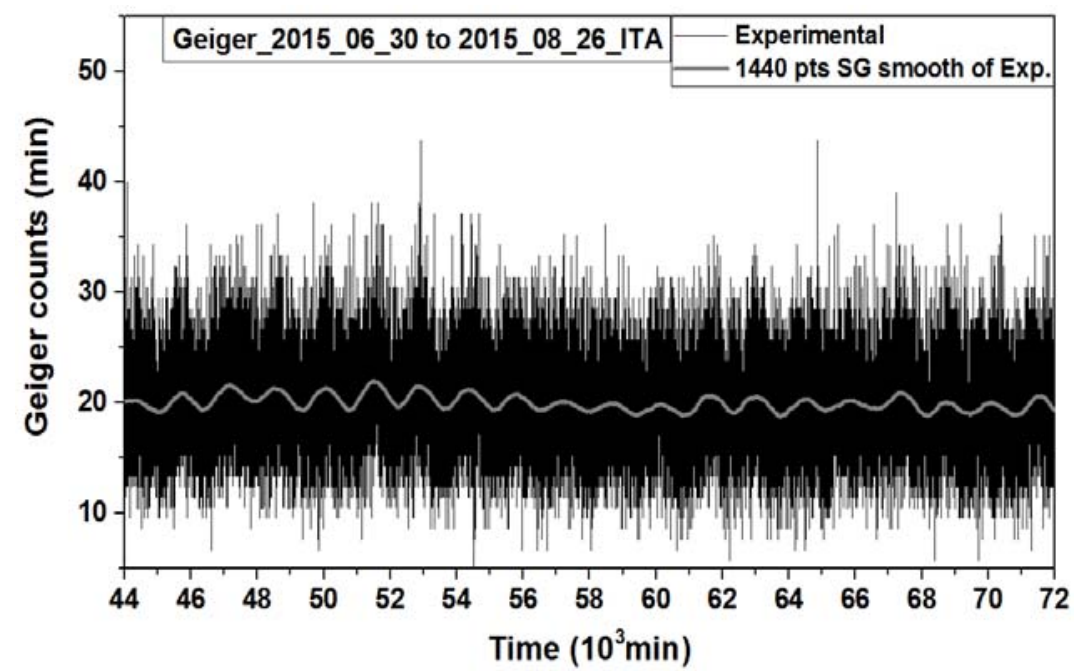

Fig. 5 Monitoring of dry period with clear evidence of one day cycles. 


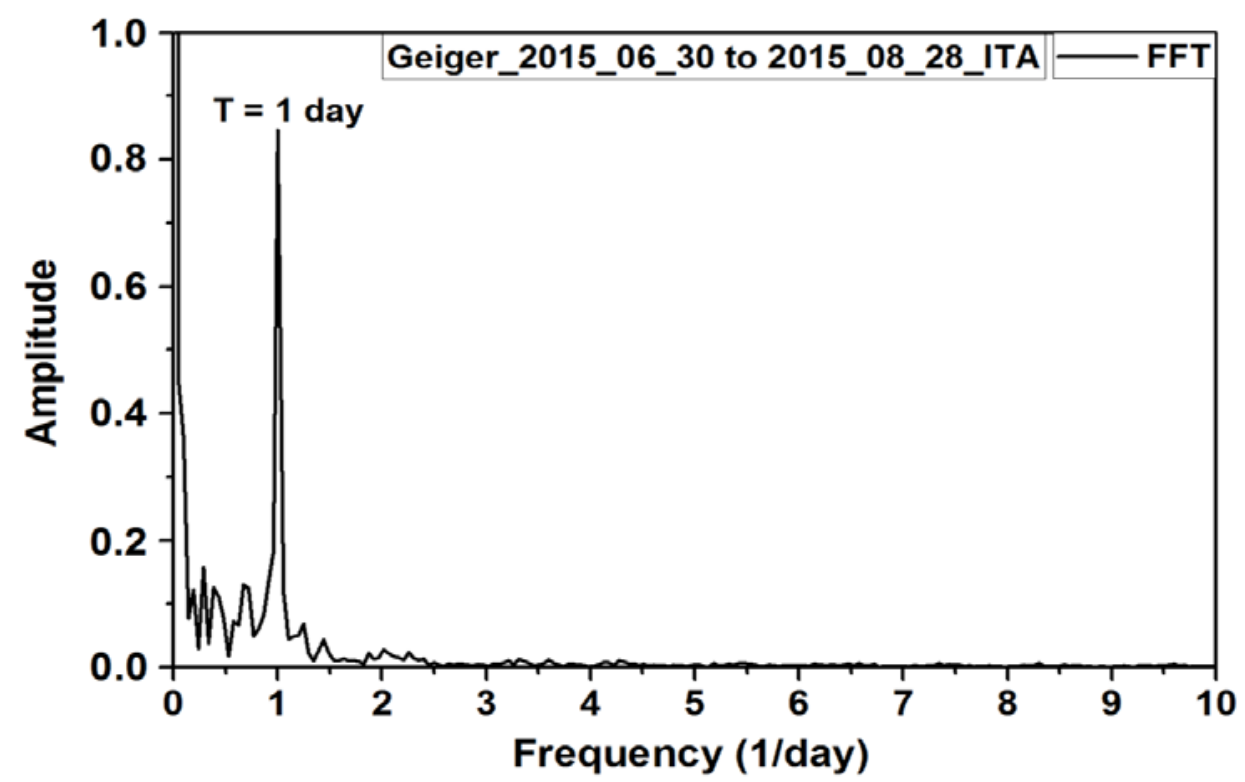

Fig. 6 Graph of Fast Fourier Transform (FFT) made from data plotted in Fig. 4, showing the cycles of 1 day with an amplitude of 0.85 relative unit (u.r.).

3-5 indicates a clear way of radon gas presence in the region (cyclesday/night). Fig. 3 with the data plotted from time interval 30/06 to 26/08 2015 was this periodicity which was visible. This period is when the rainy activity is very weak as shown in Fig. 4 and where the rains were more intense and present in March 2015. Between June and August 2015, the local rain pluviometer shows absent or very weak intensity of rain. Fig. 5 giving those Geiger measurements between the times of 44,000-55,000 minutes indicates a driest period with perfect timing cycle's (day/night). Confirmation made by this period using technique (FFT) on the data from Fig. 5 is shown in Fig. 6 leaving clear the 24 hour cycle. The variations on time of these measurements indicate the presence of radon gas in the site view through gamma radiation emitted from ${ }^{214} \mathrm{Bi}(0.609 \mathrm{MeV})$. This radiation was originated from the soil and atmosphere and detected by the Geiger. So, a simple Geiger apparatus with associated electronics and one PC can observe the variation of radon gas cycle (day/night) of a given tropical or even in the equatorial region.

\section{Conclusion}

The presence of radon gas ${ }^{222} \mathrm{Rn}$ was measured through radiation gamma emitter ${ }^{214} \mathrm{Bi}$ and ${ }^{214} \mathrm{~Pb}$ in the region of São José dos Campos, SP, Brazil. A Geiger RM-60 detector with specifications shown in (materials and methods) was used to conduct monitoring (minute by minute) between June and August 2015. In periods without rain or heavy fog, it is clear to observe the cycles of maximum intensity of gamma radiation around the middle of day and minimum around midnight in that same place. Full analysis of the Fig. 3 obtained in this period through the measurements performed by Geiger confirms the dynamic intensity of radon gas correlated with rainfall and dry weather through the presence of cycles displayed here. It is shown that one very simple tool (Geiger) for monitoring the variation of radon gas is in one specific region. This apparatus can be handled by students of secondary schools.

\section{Acknowledgments}

To CNPq Proposal 480407/2011-8 and 305145/ 2009-6, the CAPES-ITA and the Division of Fundamental Sciences, Department of Physics-Technological Institute of Aeronautics.

\section{References}

[1] Huntress, W. T., and Marov, M. Y. 2011. Soviet Robots 
in the Solar System: Mission Technologies and Discoveries. New York: Springer.

[2] Elliot, H. 1958. "The Van Allen Particules." In 5th General Assembly of CSAGI, 145-180.

[3] Campus, T. F. C. 2010. "Radon Gas Consequences on Human Health.” Cartilha Larana. Accessed September 10, 2015.

http://mail.geologia.ufrn.br/larana/downloads/cartilhalara na.pdf.

[4] Bui Van, N. A., Martin, I. M., and Júnior, A. T. 1988. "Measurements of Natural Radioactivity at Different Atmospheric Depths.” Geophysics Magazine 28 (July): 262-266.

[5] Pfafflinand, J. R., and Ziegler, E. N. 2006. Encyclopedia of Environmental Science and Engineering. Boca Raton: CRC Press.

[6] Martin, I. M. 1982. Measurements of Natural Radioactivity. Report, Science and Culture Magazine.

[7] Friedlander, G., Kennedy, J. W., Macias, D. S., and
Miller, J. M. 1981. Nuclear and Radiochemistry. New York: John Wiley \& Sons.

[8] Lima, A. A. M. 2007. "Radiation in Basic and Secondary Education.” Master thesis, University of Coimbra.

[9] Gusev, A. A., Martin, I. M., Alves, M. A., and De Abreu, A. J. 2015. "Simulation of the Radiation Fallout from Gamma-Ray Measurements.” Modeling Earth Systems and Environments 1 (3): 18-23.

[10] Martin, I. M. 1971. "Variation of the Neutron Flux and Gamma Rays of Origin Cosmic as a Function of Latitude.” Master thesis, University Toulouse III-Paul Sabatier.

[11] Gheug, N. N., Jasrotia, S., Anamika Chilsa, S. 2015. "Geiger Muller: A Thin end Window Tube Radiation Detector." International Journal of Research in Engineering and Technology 4 (5): 191-196.

[12] Hansen, J. 2015. “FFT Tutorial.” ELE-436: Communication Systems. Accessed September 18, 2015. http://www.phys.nsu.ru/cherk/fft.pdf. 